Doi: 10.5212/Uniletras.V.43.17813.2021

\title{
A ARGUMENTATIVIDADE EM TEXTOS DA ESFERA JORNALÍSTICA: UMA ANÁLISE DO GÊNERO COMENTÁRIO DE LEITOR
}

\author{
THE ARGUMENTATIVENESS IN TEXTS FROM THE \\ JOURNALISTIC SPHERE: AN ANALYSIS OF READER \\ COMMENTS GENRE
}

\author{
Maria José Fernandes da Silva Araújo* \\ Edmar Peixoto de Lima*" \\ Érika de Sá Marinho Albuquerque
}

\begin{abstract}
Resumo: O objetivo deste artigo consiste em apresentar uma análise do gênero comentário de leitor, em site jornalístico, observando de que forma o produtor do texto constrói discursivamente a argumentatividade revelada por meio de alguns elementos interacionais, dialógicos e estilísticos dos enunciados. Para tanto, teórica e metodologicamente, seguimos os postulados de Bakhtin (2016), Rojo (2005), Rodrigues (2005) e Amossy (2018). Os resultados evidenciam que os argumentos são construídos na interação entre o enunciador e seus interlocutores, que não participam face a face da comunicação, mas exercem um papel relevante nas escolhas realizadas pelo locutor. Destacamos o olhar sobre a esfera jornalística como reguladora das relações e da força argumentativa dos enunciados, que compõem o horizonte temático-discursivo do jornal, assim como as relações dialógicas com outros gêneros publicados no site, que contribuem para a orientação valorativa dos comentários de leitor.
\end{abstract}

Palavras-chave: análise argumentativa; comentário de leitor; esfera jornalística.

Aвstract: The purpose of this article is to present an analysis of the speech genre reader commenting, to online opinion journalism, observing how the writer discursively

\footnotetext{
"Doutoranda em Letras pela Universidade do Estado do Rio Grande do Norte (UERN). Mestra em Letras pela Universidade Federal do Rio Grande do Norte (UFRN). Professora de Língua Portuguesa integrante do quadro efetivo da Secretaria de Estado da Educação do Rio Grande do Norte (SEEC/RN). E-mail: masefernandes@hotmail.com.

" Doutora em Linguística Aplicada pela Universidade Estadual do Ceará (UECE). Mestra em Letras pela Universidade do Estado do Rio Grande do Norte (UERN). Professora Adjunta do Departamento de Letras Vernáculas (DLV), da Universidade do Estado do Rio Grande do Norte (UERN). Docente do Programa de Pós-Graduação em Letras da Universidade do Estado do Rio Grande do Norte (PPGL/UERN). E-mail: professoraedmar@gmail.com.

"*t" Doutoranda em Letras pela Universidade do Estado do Rio Grande do Norte (UERN). Mestra em Direito pela Universidade Católica de Pernambuco (UNICAP). Integrante da Equipe de Trabalho Remoto - Procuradoria Federal do Estado da Paraíba. E-mail: erika-albuquerque@hotmail.com.
} 
develops the argumentativeness revealed through some interactional, dialogical and stylistic elements of the statements. Therefore, theoretically and methodologically, we followed the postulates of Bakhtin (2016), Rojo (2005), Rodrigues (2005) and Amossy (2018). The results show that the arguments are built in the interaction between the speaker and his interlocutors, who do not participate face to face in the communication, but play a relevant role in the choices made by the speaker. We highlight the look upon the journalistic sphere as a regulator of the relationships and the argumentative power of the statements, which compose the thematic-discursive horizon of the web news, as well as the dialogical relations with other genres published on the website, which contribute for a value guidance of reader comments.

KEYwoRDs: argumentative analysis; reader commenting; journalistic sphere.

\section{INTRODUÇão}

Neste trabalho, objetivamos analisar o gênero comentário de leitor, em site jornalístico, observando de que modo são construídos os aspectos argumentativos revelados por meio dos elementos interacionais, dialógicos e estilísticos que integram a arquitetura discursiva do gênero. Com base na consulta aos textos selecionados para análise, assim como nas leituras previamente realizadas das teorias elencadas para este trabalho, pressupomos que a força argumentativa presente nos referidos textos reside nas características interacionais, dialógicas e de estilo próprias do gênero do discurso de que esses textos fazem parte. A nosso ver, o uso dos recursos linguísticos/lexicais também se deve às relações interacionais e dialógicas empreendidas pelo locutor, no momento da utilização desses elementos, com outros textos, de outros gêneros, também presentes no mesmo suporte (site de notícias), com os quais o locutor dialoga para construir o seu projeto de dizer.

No intuito de atender ao objetivo a que nos propomos, teórica e metodologicamente, valemo-nos dos estudos de Bakhtin (2016), Rojo (2005) e Rodrigues (2005), para as discussões em torno da temática dos gêneros do discurso, entre outros conceitos que fazem parte dos estudos bakhtinianos e que estão interligados entre si, tais como enunciado, sujeito, interação e dialogismo. Sobre as questões relativas à argumentação no discurso, ancoramos esta pesquisa nos trabalhos de Amossy (2018), especialmente no que se refere às dimensões discursivas da argumentação. Destacamos que o foco desta investigação consiste na análise do gênero comentário de leitor, observando como é construída discursivamente a argumentatividade no discurso. Desse modo, faz-se necessário considerarmos também os diálogos que são evidenciados entre os textos ${ }^{1}$ analisados e outros discursos presentes no site fonte da coleta.

\footnotetext{
${ }^{1}$ Nesta pesquisa, as autoras baseiam-se em uma perspectiva interacional e dialógica da língua. Assim, o termo texto é entendido como enunciado concreto, não apenas por sua materialidade, mas também por sua consistência enquanto entidade completa de sentido, constituindo o lugar onde os discursos se realizam (BRAIT, 2016). Por essa razão, no percurso deste artigo, utilizamos indistintamente texto e/ou discurso com o mesmo sentido.
} 
O corpus desta pesquisa é constituído por seis textos do gênero comentário de leitor, selecionados no site do Jornal Folha de São Paulo, sobre o caso do aborto da criança estuprada pelo tio, em uma cidade localizada no Espírito Santo, noticiada em agosto de 2020, nos principais jornais do Brasil. Quanto aos procedimentos metodológicos, após a seleção dos comentários, analisamos os textos seguindo o método bakhtiniano de análise dos gêneros do discurso.

Assim, orientando-nos por esse percurso e considerando os preceitos defendidos por Rodrigues (2005) e Rojo (2005), iniciamos as análises, observando os aspectos sociais que envolvem a situação de comunicação abordada, com ênfase no papel do locutor quanto à sua vontade enunciativa, a qual envolve tanto o propósito que deseja alcançar quanto a valoração deste em relação à temática e aos seus parceiros enunciativos, ou seja, os interlocutores a quem o texto se destina. Em seguida, analisamos os recursos linguísticos utilizados pelos produtores, dos quais delimitamos algumas escolhas lexicais empregadas nos textos com o objetivo de defender um ponto de vista. Além dessa sistematização, durante o processo de análise, atentamos para os diálogos que os locutores dos comentários estabelecem com outros textos/vozes, refletidos no uso das escolhas, que se constituem como elementos acionadores da argumentação.

Por apresentar uma configuração analítica sustentada por preceitos teórico-metodológicos consistentes e legitimados na comunidade acadêmica, cremos que este trabalho possibilitará a ampliação das discussões em torno das pesquisas que versam, principalmente, sobre argumentação, podendo suscitar reflexões que ensejem outros trabalhos com este viés dialógico. Ademais, as reflexões que propomos sobre a temática de que tratam os textos analisados poderão possibilitar encaminhamentos para outras investigações, uma vez que as observações evidenciadas não se encerram neste artigo.

Sob essa perspectiva, aderimos ao pensamento de Rojo (2005), quando a autora defende a análise do texto/enunciado inserido em um gênero - cujos elementos sociais (as relações estabelecidas entre os participantes) e comunicacionais são notabilizadas em primeiro plano, seguidos da análise das marcas linguísticas - não como uma análise esmiuçada dos textos, mas como um estudo que nos possibilita caracterizar, em certa medida, o gênero do discurso.

Sendo assim, a fundamentação teórica, expressa após esta introdução, está dividida em duas seções que tratam sobre os gêneros do discurso e a argumentação, respectivamente. Cada percurso teórico adotado apresenta seus respectivos parâmetros por meio das quais buscamos atingir o objetivo deste trabalho, no entanto, essas teorias mantêm, entre si, correlações tanto teóricas quanto metodológicas. Na segunda seção, discorremos sobre os gêneros do discurso na perspectiva bakhtiniana, abordando, também, outros conceitos que estão atrelados a essa temática, e, na terceira, expomos as discussões sobre a Argumentação no discurso, considerando as concepções defendidas por Amossy (2018). Com relação aos preceitos analíticos empreendidos na pesquisa, apresentamos as considerações realizadas no âmbito da situação social e enunciativa de produção do gênero, seguidas da análise de alguns recursos linguísticos 
que funcionam, a nosso ver, como acionadores dos aspectos argumentativos, e, para finalizar esta exposição, recorremos às considerações finais e à organização das referências.

Em suma, consideramos que os princípios teóricos e metodológicos empreendidos nesta investigação se configuram em recursos necessários para o entendimento da organização argumentativa do texto, com enfoque no propósito de adequação do locutor aos posicionamentos, que ele acredita serem defendidos pelo interlocutor, na tentativa de influenciá-lo de algum modo por meio dos discursos.

\section{OS GÊNEROS DO DISCURSO EM BAKHTIN: ASPECTOS TEÓRICO-METODOLÓGICOS}

Para tratarmos sobre os gêneros do discurso, adotamos a concepção bakhtiniana, segundo a qual não é possível dissociar a linguagem do âmbito das atividades humanas. De acordo com essa perspectiva, a comunicação se materializa por meio de enunciados, sejam eles escritos ou orais, inseridos em ambientes temáticos específicos que exigem o enquadramento de um estilo de linguagem, compondo, desse modo, uma estrutura linguística própria para determinadas situações comunicativas. Os gêneros do discurso, como são denominados os diferentes tipos de enunciados na visão bakhtiniana, são diversificados e heterogêneos, no que se refere às funcionalidades e às formas, apresentando certa estabilidade, a depender dos campos do saber de que fazem parte. Assim, compreender em que consiste o enunciado, além de outros conceitos que perpassam esses estudos, tais como sujeito e dialogismo, é condição para o entendimento profícuo sobre os gêneros e, consequentemente, para a análise destes.

Bakhtin (2016) define os enunciados como unidades reais da comunicação discursiva, destacando a representatividade que eles exercem nos contextos enunciativos e nos propósitos comunicativos de qualquer esfera do conhecimento, pois cada campo de utilização da língua apresenta um conjunto de enunciados próprios, os gêneros do discurso. Mesmo diante de diversos contextos situacionais - como o social, o político, o jurisdicional, por exemplo em que se desenvolvem, os enunciados se vinculam a campos semelhantes de comunicação. Cada época ou grupo social apresenta as suas especificidades, as suas características próprias que, necessariamente, influenciarão o processo discursivo que se desenvolve por meio de relações dialógicas.

Em virtude da heterogeneidade intrínseca aos enunciados, o autor supramencionado classifica os gêneros do discurso em primários e secundários. Estes são mais complexos, porque são resultantes de relações sociais e culturais mais complexas, enquanto aqueles são mais simples e comuns, porque estão presentes no cotidiano e representam, de certo modo, os diálogos orais. São justamente os fatores culturais e ideológicos, inerentes ao processo de sua formação, os aspectos que os diferenciam. 
Nesse sentido, os estudos sobre a língua devem partir dessa concepção de enunciado, de textos concretos e, por conseguinte, precisam considerar o quadro genérico em que os enunciados se organizam, para que, de fato, seja possível compreender a sua natureza, condição fundamental, na visão de Bakhtin (2016), para a compreensão da língua. Ao discorrer sobre as peculiaridades dos enunciados, o filósofo da linguagem trata inicialmente sobre o estilo, destacando esse componente como revelador das características individuais do falante e de certas unidades temáticas e composicionais, por meio das quais as relações sociais se manifestam.

Ainda no que se refere às especificidades do enunciado, Bakhtin (2016) adverte sobre o cuidado em sabermos diferenciar essa unidade da comunicação discursiva e os elementos lexicais e gramaticais da língua. Os enunciados provocam no interlocutor uma resposta - mesmo que isso ocorra de forma passiva -, ao contrário dos elementos puramente linguísticos. Tal fato (a responsividade enunciativa) nos leva à reflexão proposta pelo autor sobre a conclusibilidade do enunciado, que se refere à alternância dos sujeitos do discurso, cuja análise deve ser realizada com base em categorias genéricas específicas e precisa também levar em conta alguns elementos, a saber, o tema do enunciado, o projeto discursivo do falante e as formas composicionais do gênero.

Para analisarmos a composição estilística dos enunciados, faz-se necessária a observação de alguns critérios, como o propósito mobilizado pelo autor e a relação desse com o enunciado, tendo em vista que as escolhas linguísticas ocorrerão com base no seu projeto de dizer. Nesse processo, o falante recorre a enunciados já conhecidos e que integram os gêneros do discurso, cujas formas são consideradas tipicamente organizadas e situadas. Para Bakhtin (2016), conhecer o campo de atividade e o contexto social em que os enunciados são empregados é um aspecto determinante na caracterização destes, pois os sujeitos dialogam permanentemente com esses elementos e com outros enunciados já ditos, na constituição dos seus discursos.

É neste ponto que elencamos o dialogismo bakhtiniano, conceito que transcorre, conforme mencionamos no início desta seção, as discussões sobre os gêneros. As relações dialógicas que o falante empreende, seja com outros enunciados ou com sujeitos distintos, exercem enorme influência na caracterização estilística do enunciado, construída a partir das escolhas disponíveis no sistema da língua, mas inspirada pelo objeto do discurso e pela inter-relação que o sujeito constrói com este objeto, de forma valorativa. Por essas razões, os enunciados são sempre dialógicos e as relações ocorrem nos diferentes campos da comunicação discursiva.

De acordo com a perspectiva bakhtiniana, para se reportar ao objeto discursivo, o enunciado se vale dos discursos outros. Eles têm autoria e são endereçados a um interlocutor cujas características também interferem na definição do gênero do discurso, no estilo e na estrutura composicional dos enunciados, exercendo, portanto, acentuada influência na sua construção, desde o planejamento até a concretização do discurso. 
É por meio deste entendimento que buscamos conhecer algumas especificidades do gênero do discurso comentário de leitor, considerando, na investigação, o campo de comunicação em que este se apresenta (a esfera jornalística). Ao considerarmos, nesse processo de análise, a concepção de enunciado em Bakhtin (2016), compreendemos de fato como as relações comunicativas reais acontecem, como se dão os processos dialógicos que ocorrem na interação entre o enunciador e seus interlocutores. É nesse contexto que surge a necessidade de se conhecer o estilo e, por intermédio dele, identificar a forma e o tema do enunciado, bem como a individualidade do enunciador, considerando que esse sujeito poderá apresentar características distintas, a depender do gênero discursivo em que se inscreve o texto.

O estudo das relações entre os componentes do gênero do discurso - o estilo, o tema e a estrutura composicional - evidencia que eles resultam da situação comunicativa em que são produzidos os enunciados. Além do contexto de produção, o juízo de valor atribuído pelo locutor ao destinatário do discurso e ao conteúdo temático, que apresenta um propósito e um acabamento, determinam os traços estilísticos, temáticos e composicionais dos gêneros. Esse modo de caracterizar o enunciado está diretamente ligado ao pensamento de Bakhtin (2016) sobre o sujeito, que se inscreve no discurso, sócia, histórica e situadamente. Sobre esse aspecto, Rojo (2005, p. 197, grifos da autora) esclarece:

São elementos essenciais desta situação social mais imediata os parceiros da interlocução: o locutor e seu interlocutor, ou horizonte/auditório social, a que a palavra do locutor se dirige. São as relações sociais, institucionais e interpessoais desta parceria, vistas a partir do foco da apreciação valorativa do locutor, que determinam muitos aspectos temáticos, composicionais e estilísticos do texto ou discurso.

Tomando por base essas propriedades teóricas que envolvem o estudo dos gêneros do discurso em Bakhtin (2016), trataremos, neste ponto, sobre alguns aspectos do método sociológico de análise do enunciado que seguiremos para a análise do gênero comentário de leitor em site jornalístico. Conforme aponta Rojo (2005, p. 198), para estudarmos a língua seguindo essa orientação metodológica, devemos desenvolver as análises na seguinte ordem: "1) As formas e os tipos de interação verbal em ligação com as condições concretas em que se realiza. 2) As formas das distintas enunciações, dos atos de fala isolados [...]. 3) A partir daí, exame das formas da língua em sua interpretação linguística habitual". Sob essa perspectiva, defendemos que é no enquadramento das relações sociais que se desenvolve a comunicação, que, por sua vez, promove a evolução das enunciações isoladas e, consequentemente, permite que todo esse processo se manifeste na materialidade textual, cujas formas linguísticas (lexicais e gramaticais) mais expressivas devem ser evidenciadas em última instância.

Os recursos lexicais, assim como os gramaticais, caracterizadores do estilo do gênero, constituem componentes relevantes na análise dos diferentes discursos. Sobre essa questão, 
Rodrigues (2005, p. 168) lembra que "[o] estilo de um enunciado particular pode ser mais bem compreendido ao se considerar a sua natureza genérica. Os estilos individuais, bem como os da língua, são estilos do gênero". Desse modo, a análise dos recursos linguísticos utilizados pelos produtores, em consonância com a observação primeira das instâncias sociais (interação autor/leitor, lugares sociais, esfera comunicativa) nos permitirão compreender algumas características do gênero comentário de leitor e os aspectos argumentativos que os integram.

Trilhando, portanto, este percurso de análise dos gêneros do discurso, inicialmente, faremos as considerações acerca da situação de enunciação em que os textos (comentários de leitor) são produzidos, elencando as informações de caráter histórico e social que, a nosso ver, são relevantes para esta análise. Nessas considerações, enfatizamos o propósito do enunciador e a valoração perceptível deste em relação à temática abordada e aos interlocutores, consoante orienta Rodrigues (2005) e Rojo (2005). Em seguida, destacamos alguns recursos linguísticos que, por estarem atrelados pragmaticamente aos aspectos sociais, interacionais e enunciativos pautados anteriormente, funcionam como elementos acionadores da argumentatividade do referido gênero. Os subsídios teóricos que adotamos neste trabalho, para tratar sobre a argumentação, fazem parte dos fundamentos da Análise Argumentativa do Discurso, os quais abordamos nesta próxima seção.

\section{A ARgumentação No Discurso: PRINCípIos E/OU ABORDAgeNS PARA A ANÁlISE ARGUMENTATIVA}

A Análise Argumentativa do Discurso, na perspectiva de Amossy (2018), é uma abordagem teórico-metodológica dos estudos argumentativos que visa compreender as dimensões discursivas da argumentação. Vinculada à Análise do Discurso de orientação francesa, essa vertente apresenta alguns princípios por meio dos quais devem ser realizados os procedimentos de análise textual. Dentre outros pontos de vista teóricos, esses preceitos assumem também um enfoque interacionista, indo, desse modo, ao encontro do método de análise proposto por Bakhtin, em vários aspectos, mas, principalmente, no tocante à concepção do sujeito, das relações dialógicas e dos gêneros do discurso. Sob esse viés, o sujeito é compreendido conforme os papéis sociais desempenhados; as relações dialógicas são defendidas pela autora como uma característica inerente aos discursos; e os gêneros, quadros discursivos em que se inscrevem os textos, são componentes indispensáveis ao desenvolvimento da argumentação.

Conforme esclarece a autora supracitada, essa abordagem argumentativa objetiva estudar a argumentação no âmbito do discurso, analisando-o tanto do ponto de vista de uma visada quanto de uma dimensão argumentativa. Nesse processo, a análise é realizada a partir de um tratamento linguageiro, comunicacional, dialógico, genérico, figural e textual (AMOSSY, 2018), e essas formas fazem parte, em alguma medida, do processo analítico proposto. Para as análises que empreendemos neste trabalho, priorizamos as abordagens genérica e dialógica, 
seguidas da análise linguageira, tendo em vista as aproximações entre esses componentes e os postulados teórico-metodológicos que adotamos de Bakhtin (2016).

No tocante à abordagem que contempla os gêneros do discurso, Amossy (2018. p. 41), defende:

A argumentação se inscreve sempre num tipo e num gênero de discurso, mesmo que ela os subverta ou escolha se inscrever de modo complexo a diversos gêneros já repertoriados. O gênero do discurso, em relação direta com a sociedade que o institucionaliza, determina finalidades, quadros de enunciação e uma distribuição prévia dos papéis.

Ao questionar sobre a proporção tomada pela argumentatividade no discurso, Amossy (2018) nos lembra que a análise argumentativa deve ser aplicada às práticas sociais de linguagem, pois o foco dessa abordagem está nos discursos em funcionamento, ou seja, nos textos reais. Essa é a razão por que os gêneros ocupam um lugar privilegiado nesta vertente. Há gêneros que possuem uma força argumentativa maior, sendo, portanto, persuasivos, porque apresentam uma visada, enquanto há outros menos argumentativos, que manifestam uma dimensão, buscando muitas vezes orientar o leitor. Tais características dependem, entre outros critérios, do propósito a que o texto se destina.

A análise da argumentação inscrita no discurso leva em conta uma abordagem dialógica, cujo enfoque sustenta que "[a] argumentação pretende agir sobre um auditório e, por isso, deve adaptar-se a ele. Ela participa da troca entre parceiros [...]. Além disso, intervém num espaço já saturado de discurso, reagindo àquilo que se disse e que se escreveu antes dela [...]" (AMOSSY, 2018, p. 41). De acordo com esse pensamento, cujos princípios repousam na concepção bakhtiniana sobre a natureza essencialmente dialógica da linguagem, todo dizer emerge a partir de outros dizeres, com os quais dialoga. Sobre essa questão, Bakhtin/ Volóchinov (1977, p. 105 apud Amossy, 2018, p. 42) assevera: “[t]oda enunciação [...] é uma resposta a alguma coisa e se constrói como tal. Ela é um elo na cadeia dos atos de fala. Toda inscrição prolonga aquelas que a precederam, inicia uma polêmica com elas, prevê reações ativas de compreensão e as antecipa”.

A partir de tais reflexões, Amossy (2018) aponta a argumentatividade inscrita no discurso como uma consequência das relações dialógicas que são estabelecidas e que são próprias de todo discurso. Daí emerge a pressuposição elencada não apenas por esta autora, mas também por outros estudiosos da área, de que todo texto/discurso é, em alguma medida, argumentativo, dado que a argumentação se encontra arraigada no discurso. Isso acontece porque, mesmo quando o locutor não tem a intenção de persuadir o outro, ele o provoca de alguma forma, a participar, a agir por meio do discurso.

Com isso, retomamos a discussão empreendida por Amossy (2018) sobre o papel da Análise Argumentativa do Discurso, que toma como objeto de análise textos concretos, enunciados em situações de uso real e, por essa razão, considera que todos eles apresentam 
argumentatividade. No entanto, a autora adverte sobre a diferença entre a dimensão argumentativa, que é própria de inúmeros discursos, da visada argumentativa, restrita a alguns. Vejamos:

Para evitar as confusões, é preciso, porém, diferenciar a dimensão argumentativa inerente a muitos discursos, da visada argumentativa que caracteriza apenas alguns deles. Em outros termos, a simples transmissão de um ponto de vista sobre as coisas, que não pretende expressamente modificar as posições do alocutário, não se confunde com uma empreitada de persuasão sustentada por uma intenção consciente e que oferece estratégias programadas para esse objetivo. Uma defesa no tribunal tem uma nítida visada argumentativa [...]. Uma descrição jornalística ou romanesca, entretanto, terá mais uma dimensão do que uma finalidade argumentativa (AMOSSY, 2018, p. 44).

A argumentatividade presente nos textos pode apresentar, portanto, modalidades diversas, a depender, como já mencionamos, dos objetivos do discurso. Entretanto, não é possível ao analista quantificar essa força argumentativa. É nesse ponto que os gêneros do discurso ganham destaque na análise da argumentação, pois sendo o enunciado mais ou menos argumentativo, "a argumentação [dependerá] diretamente do quadro discursivo no qual ela se desenvolve” (AMOSSY, 2018, p. 243).

A Análise Argumentativa do Discurso passa também por uma abordagem linguageira. Nessa esteira, a argumentação é construída a partir dos recursos linguísticos que se encontram à nossa disposição. Entre esses recursos, que são muitos e variados, estão as escolhas lexicais que os produtores dos textos utilizam e que podem funcionar como acionadores da argumentação (AMOSSY, 2018). Além dessas formas de abordagens - genérica, dialógica e linguageira - que destacamos por apresentarem características equivalentes à proposta de análise desta pesquisa, a autora sustenta que a análise da argumentação no discurso configura-se também como uma abordagem comunicacional, porque toda situação comunicativa é realizada por sujeitos que se relacionam; figural, porque a argumentação às vezes é construída através das figuras de estilo; e textual, sendo o texto entendido, nessa perspectiva, como uma entidade completa de sentidos.

Desse modo, a Análise Argumentativa do Discurso (AMOSSY, 2018) fornece instrumentos teóricos e metodológicos que contêm mecanismos linguísticos e extralinguísticos por meio dos quais podemos analisar os mais diferentes tipos de discursos, que apresentam maior ou menor força argumentativa, e que se enquadram nos mais diversificados gêneros e formações discursivas, entre os quais destacamos o comentário de leitor. Essa concepção consiste, portanto, em uma dimensão ampla dos estudos argumentativos, que objetiva compreender a argumentação pela via dos discursos e das formas como esses funcionam nas mais diversas situações de uso da linguagem. Nessa empreitada, a observação da materialidade textual (linguageira) é condição necessária para o entendimento da argumentação. 
Tomando por base esses pressupostos teóricos, passamos à análise do gênero comentário de leitor em site jornalístico, observando o modo como são construídos os aspectos argumentativos nos textos selecionados.

\section{ANÁLISE ARGUMENTATIVA DO GÊNERO COMENTÁRIO DE LEITOR EM SITE JORNALÍSTICO}

Os textos que elegemos para constituírem o corpus deste trabalho foram coletados no site $\mathrm{Uol}^{2}$, Folha de São Paulo, um jornal de grande circulação nacional. Conforme já mencionamos, esses textos pertencem ao gênero comentário de leitor e, por meio deles, os produtores, que também são leitores deste jornal, comentam um fato noticiado algumas horas antes, no mesmo jornal, em edição do dia 18 de agosto de 2020 . Na notícia, intitulada "Menina de dez anos entrou em hospital em porta-malas de carro enquanto médico distraía religiosos", dois jornalistas narram o episódio de uma criança capixaba de apenas dez anos que, após sofrer vários estupros do próprio tio e engravidar, é perseguida e assediada por fanáticos religiosos e políticos que protestavam na frente da unidade hospitalar onde a menina iria se submeter ao aborto, concedido legalmente. Ao comentarem sobre esse acontecimento, que teve enorme repercussão nacional, os leitores criticam o comportamento dos manifestantes, que bloqueavam as entradas do hospital, na tentativa de impedir a criança de realizar o procedimento, assim como também criticam a falta de posicionamento de católicos sobre o caso.

A seguir, expomos os comentários, sem a identificação dos autores. Atribuímos aos textos a codificação CL1, CL2, CL3, CL4, CL5, considerando que CL significa comentário de leitor e os números indicam a sequência em que eles estão dispostos no presente artigo.

CLI

Uma menina de dez anos! Passou todo o tempo abraçada a um bicho de pelúcia! [...] Meu Deus, grande parte da Igreja Católica e o pior dos evangélicos juntos no mesmo hediondo protesto contra o aborto. [...] Permitam-me, por favor, me afastar da igreja?

\section{CL2}

Se, para a igreja, toda gravidez deve ser fruto do amor entre duas pessoas, por qual motivo os conservadores dessas denominações religiosas brigam para que uma criança de 10 anos (dez anos!) mantenha uma gravidez fruto de um crime e que será prejudicial à saúde dela e do bebê? Não venham dizer que é porque são a favor da vida. Essa gravidez é de altíssimo risco para as duas crianças envolvidas. É incoerência, para dizer o mínimo.

\footnotetext{
${ }^{2}$ Disponível em: https://www1.folha.uol.com.br/paineldoleitor/2020/08/leitores-comentam-caso-do-aborto-da-crianca-estuprada-no-es.shtml. Acesso em: 08 set. 2020.
} 
CL3

Esses fascistoides travestidos de cristãos deveriam ser todos enquadrados pela justiça por terrorismo, obstrução de justiça e outros crimes. Aberração típica de um ajuntamento de fanáticos.

CL4

Não consigo parar de pensar no horror que essa criança sofreu e continua sofrendo. Primeiro, um monstro abusou da criança por quatro anos. Agora, grupos que se dizem religiosos não defendem a menina, não a apoiam, não a ajudam. Mobilizam-se para xingar médicos em vez de se voltarem contra o verdadeiro criminoso: o tio. Desejo que essa menina encontre pessoas que realmente sigam o verdadeiro Deus. Aquele que cuida, zela, protege e defende quem mais precisa.

CL5

Só neste país essas loucuras acontecem. Fanatismo só gera violência. Há exemplos pelo mundo todo. São pessoas desprovidas de amor e de compaixão, que se esforçam para parecerem normais, usando como escudo a Bíblia e Deus. Esses atos abjetos de pessoas sem caráter têm que ser punidos exemplarmente. A justiça e o congresso são omissos.

CL6

E, como é público e notório quando crimes similares contra crianças ocorrem no seio da própria Igreja Católica, não há nenhuma indignação por parte desses fascistoides.

O gênero do discurso comentário de leitor enquadra-se na esfera cotidiana, por ser simples, comum, apresentar traços da oralidade, compreendendo, assim, um gênero primário. No entanto, a depender dos suportes em que circulam os gêneros, especialmente, os digitais, e do propósito comunicativo, ele pode alcançar diferentes características no sentido de enquadrar-se em outras esferas, como a jornalística. Do mesmo modo que a carta de leitor, os comentários são veiculados geralmente em jornais e revistas, e configuram-se em textos que apresentam opiniões, sugestões e/ou críticas advindas dos leitores sobre alguns dos temas abordados, sendo, portanto, um gênero opinativo por meio do qual o produtor demonstra sua percepção sobre os fatos sociais noticiados, com base em argumentos. Assim, os locutores são os próprios leitores do veículo de comunicação e os interlocutores são representados por quaisquer pessoas interessadas no assunto, também leitores, que têm acesso ao jornal, não sendo possível classificar com precisão esse público. 
A princípio, chama-nos a atenção o dialogismo fortemente perceptível nos comentários, fato que não causaria nenhuma admiração se considerássemos apenas que primeiro os leitores leem a notícia para, depois, comentá-la, estabelecendo relações dialógicas diretas com o texto que veicula os fatos. Entretanto, além desse diálogo entre os textos que estão no site, os leitores encadeiam seus dizeres a discursos vários, os quais são construídos socialmente na vivência de cada um deles, extrapolando, em algumas situações, os fatos que estão postos na notícia, texto base para a produção dos comentários.

A própria natureza do suporte ou o ambiente de publicação dos textos, que se caracteriza por conter inúmeros recursos digitais e midiáticos, favorece a relação dialógica entre os discursos. Exemplos disso são os links, que direcionam os leitores dos comentários às notícias publicadas anteriormente sobre o mesmo caso, além de outros gêneros que compõem a página dos comentários, como uma charge com teor crítico, da cartunista Laerte, intitulada "Defesa da vida" e a fotografia de um cartaz fixado no hospital de Recife onde a criança fez o aborto, no qual se lê "A culpa nunca é da vítima”. Esses outros gêneros contribuem tanto para a construção de sentido dos comentários quanto para atrair a atenção dos internautas leitores.

O dialogismo constitui um aspecto imprescindível na construção argumentativa dos enunciados, pois funciona, na visão de Amossy (2018), como uma consequência das relações dialógicas que são estabelecidas e que são próprias de todo discurso. Este primeiro ponto que destacamos percorrerá, como veremos, as demais questões elencadas nas análises.

Seguindo os estudos de Rodrigues (2005, p. 170), no tocante aos aspectos sociais inerentes à situação comunicativa dos comentários em análise, destacamos, inicialmente, algumas peculiaridades da esfera jornalística, como a interação entre autor/leitor, que não se realiza face a face e cuja mediação ocorre "ideologicamente". De acordo com a autora, a "esfera jornalística [...] 'regulamenta' as diferentes interações nesse espaço, 'filtra', 'interpreta' (impõe um acento de valor) e põe em evidência os fatos, acontecimentos, saberes, opiniões etc. que farão parte do universo temático-discursivo jornalístico" (RODRIGUES, 2005, p. 170-171, grifos da autora). Nesse aspecto, a forma como os textos em estudo está organizada no site (os comentários, que fazem parte da seção "painel do leitor", em conexão direta com a notícia, publicada na seção "cotidiano") evidencia o propósito interacional do jornal, que, por meio da notícia, veicula os fatos de forma impessoal, objetiva e, com a abertura para a publicação de comentários dos leitores sobre o fato noticiado, regula de forma valorativa o conteúdo temático abordado nos textos. Além disso, os demais gêneros publicados na seção dos comentários (a charge e o cartaz, por exemplo) reforçam a carga axiológica dos posicionamentos dos leitores/produtores dos comentários em relação aos fatos noticiados.

Quanto ao lugar social ocupado pelos locutores dos textos, podemos dizer que esses representam uma parcela da população, os leitores do Jornal Folha de São Paulo, mas, ao mesmo tempo, representam também o jornal, porque é neste espaço que estão sendo veiculados os comentários e, antes de serem publicados, passam por um processo de seleção, fato 
que comprova a adesão da Folha de São Paulo às ideias defendidas nos comentários. Nesse aspecto, a opinião, mesmo sendo pública e expressando de forma acentuada os valores e as crenças sobre a atitude dos manifestantes ("fanáticos religiosos e políticos") em relação ao aborto legal a que se submetia a criança vítima de estupro, é regulada pela esfera jornalística, que organiza, medeia a interação promovida pelo referido jornal e permite, por meio dos comentários, a ancoragem com outros discursos, pluralizando a abordagem temática do aborto quando realizado em caso de estupro. Esse enfoque na dimensão social do gênero comentário de leitor é imprescindível ao processo da análise argumentativa do discurso, como abordamos na seção teórica com base em Amossy (2018).

De acordo com Rodrigues (2005, p. 172), “[a] pluralidade ideológica e o caráter de abertura para a manifestação da opinião externa à empresa são, na verdade, uma imagem construída pela esfera jornalística". Então, mesmo se tratando de uma notícia, que veicula as informações nas quais os comentários se baseiam, o texto evidencia a valoração dada às opiniões dos leitores, pelo jornal, ao selecionar comentários que expressam uma atitude de reprovação dos manifestantes. Nessa esteira das reflexões, entendemos que há conformidade entre a opinião dos leitores comentaristas e o posicionamento do jornal - mesmo que de maneira indireta - no tocante à vontade enunciativa de ambos, ou seja, ao propósito comunicativo que desejam alcançar e, ainda, no ethos discursivo construído pelos comentaristas, que, de acordo com Amossy (2018, p. 91), corresponde à "imagem que o locutor projeta de si mesmo em seu discurso, tal como ela se inscreve na enunciação, mais do que o enunciado, e a maneira como ele reelabora os dados pré-discursivos".

Nesse sentido, a julgar pelo conteúdo temático dos comentários em estudo, cujos enunciados dialogam com diferentes campos da comunicação discursiva (religioso principalmente, mas também jurídico e da saúde), compreendemos que o ethos revelado pelos locutores incorpora todos esses discursos que funcionam nos textos em análise como argumento de autoridade e de credibilidade. Essa percepção vai ao encontro do que Rodrigues (2005) defende quando analisa o gênero artigo de opinião seguindo a abordagem bakhtiniana. Apesar de serem gêneros diferentes - artigo de opinião e comentário de leitor -, os locutores de ambos compartilham dessas manifestações expressas de maneira valorativa sobre os fatos sociais. Desse modo, entendemos que o caráter ideológico que compõe os textos (perceptível no ethos evidenciado pelos locutores) resulta dos componentes discursivos que o integram, ou seja, das características do gênero do discurso. Com isso, mais uma vez nos reportamos à discussão proposta por Amossy (2018) sobre a necessidade de levarmos em conta os quadros genéricos na análise argumentativa dos discursos, visto que a argumentatividade presente nos enunciados surge nas situações de uso real, cujas temáticas, como é o caso dos comentários em análise, enquadram-se em um estilo de linguagem e compõem, todos eles (tema e estilo), a estrutura composicional do gênero. 
Após essas considerações realizadas no âmbito da situação social e enunciativa em que os comentários foram produzidos, passamos à análise de alguns recursos linguísticos que funcionam como acionadores dos aspectos argumentativos. Mesmo sendo uma abordagem linguageira (AMOSSY, 2018), ela não ocorre de forma desvinculada dos aspectos sociais, interacionais e enunciativos que elencamos com base em Bakhtin (2016) e adotados por Rodrigues (2005). Assim, para compreendermos o estilo dos enunciados que compõem os comentários e o valor argumentativo impresso no uso de algumas escolhas realizadas pelos enunciadores, consideraremos também a sua natureza genérica, conforme orientam as teorias adotadas neste trabalho.

No quadro seguinte, expomos os recursos linguísticos que destacamos (em negrito) para análise:

Quadro 1 - Recursos linguísticos analisados na pesquisa.

\begin{tabular}{|c|c|}
\hline CLI & $\begin{array}{l}\text { Uma menina de dez anos! Passou todo o tempo abraçada a um bicho de pelúcia! [...] Meu } \\
\text { Deus, grande parte da Igreja Católica e o pior dos evangélicos juntos no mesmo hediondo } \\
\text { protesto contra o aborto. [...] Permitam-me, por favor, me afastar da igreja? }\end{array}$ \\
\hline CL2 & $\begin{array}{l}\text { Se, para a igreja, toda gravidez deve ser fruto do amor entre duas pessoas, por qual motivo } \\
\text { os conservadores dessas denominações religiosas brigam para que uma criança de } 10 \text { anos } \\
\text { (dez anos!) mantenha uma gravidez fruto de um crime e que será prejudicial à saúde dela } \\
\text { e do bebê? Não venham dizer que é porque são a favor da vida. Essa gravidez é de altíssimo } \\
\text { risco para as duas crianças envolvidas. É incoerência, para dizer o mínimo. }\end{array}$ \\
\hline CL3 & $\begin{array}{c}\text { Esses fascistoides travestidos de cristãos deveriam ser todos enquadrados pela justiça por } \\
\text { terrorismo, obstrução de justiça e outros crimes. Aberração típica de um ajuntamento de } \\
\text { fanáticos. }\end{array}$ \\
\hline CL4 & $\begin{array}{l}\text { Não consigo parar de pensar no horror que essa criança sofreu e continua sofrendo. } \\
\text { Primeiro, um monstro abusou da criança por quatro anos. Agora, grupos que se dizem } \\
\text { religiosos não defendem a menina, não a apoiam, não a ajudam. Mobilizam-se para xingar } \\
\text { médicos em vez de se voltarem contra o verdadeiro criminoso: o tio. Desejo que essa } \\
\text { menina encontre pessoas que realmente sigam o verdadeiro Deus. Aquele que cuida, zela, } \\
\text { protege e defende quem mais precisa. }\end{array}$ \\
\hline CL5 & $\begin{array}{l}\text { Só neste país essas loucuras acontecem. Fanatismo só gera violência. Há exemplos pelo } \\
\text { mundo todo. São pessoas desprovidas de amor e de compaixão, que se esforçam para } \\
\text { parecerem normais, usando como escudo a Bíblia e Deus. Esses atos abjetos de pessoas } \\
\text { sem caráter têm que ser punidos exemplarmente. A justiça e o congresso são omissos. }\end{array}$ \\
\hline CL6 & $\begin{array}{l}\text { E, como é público e notório quando crimes similares contra crianças ocorrem no seio da } \\
\text { própria Igreja Católica, não há nenhuma indignação por parte desses fascistoides. }\end{array}$ \\
\hline
\end{tabular}

Fonte: Elaboração própria.

Outros recursos poderiam também ser analisados, porém selecionamos estes que estão grifados em negrito por corresponderem aos elementos mais expressivos, a nosso ver, da argumentatividade nestes textos. Baseando-nos na pesquisa de Rodrigues (2005), entendemos que 
essas escolhas linguísticas evidenciam o acento de valor expresso pelos locutores em relação ao comportamento das pessoas que protestavam contra o aborto que a criança realizaria, relatado na notícia. Elas integram um tema que emerge da notícia publicada no site, geradora dos comentários, mas expandem esse ambiente temático por intermédio das relações dialógicas que os enunciadores estabelecem com outros enunciados, de campos diferentes, para se dirigirem aos seus interlocutores, que também são leitores do jornal e, por isso, coparticipam do mesmo universo sociocultural e temporal. Assim, os discursos contidos nos comentários, ao mesmo tempo em que marcam a individualidade do locutor, espelham as reações dos leitores aos fatos da notícia e, como vimos, são carregados de argumentos contrários ao comportamento dos manifestantes.

Os diálogos estabelecidos com os outros discursos e expressos por meio dos recursos que a língua disponibiliza instituem a base para a argumentatividade dos textos. As escolhas, nesse caso, funcionam como acionadores dos aspectos argumentativos, mas elas sozinhas não constroem os argumentos, mesmo que sejam dotadas de significados e de um determinado valor axiológico (AMOSSY, 2018). Desse modo, são as propriedades do gênero, que estão enquadradas no nível discursivo, que possibilitam ao locutor argumentar por meio das escolhas linguísticas e compor, assim, a orientação valorativa do texto.

Os recursos em destaque caracterizam a configuração estilística dos comentários observados. Os locutores salientam, com base nessas escolhas, seus lugares sociais, que correspondem claramente a um lugar ocupado por pessoas comuns, que se sentem indignadas diante do posicionamento de outras pessoas que são contrárias ao aborto, em qualquer circunstância - até mesmo neste caso em que a vítima (de estupro) é uma criança de 10 anos - e, para isso, revestem-se de um discurso religioso para justificarem seus atos.

A voz do locutor (que integra a esfera cotidiana e, nesse contexto, também a jornalística) representa a opinião pública, marcada na textualidade por construções interlocutivas (Meu Deus; Permitam-me, por favor, me afastar da igreja? -CL1), exclamativas (Uma menina de dez anos! - CL1; dez anos! - CL2); unidades lexicais que indicam repulsa (aberração; fanáticos - CL3; horror; monstro; criminoso - CL4; fascistoides - CL6), aprovação, referindo-se ao "verdadeiro Deus" (cuida, zela, protege, defende - CL4); sintagmas nominais formados por substantivo e adjetivo (hediondo protesto - CL1; altíssimo risco - CL2; fascistoides travestidos de cristãos - CL3; verdadeiro Deus - CL4; pessoas sem caráter - CL5); construções oracionais do senso comum (grupos que se dizem religiosos -CL4; fanatismo só gera violência; usando como escudo a Bíblia e Deus - CL5).

Essas escolhas, ao serem analisadas pela via do discurso, deixam de ser apenas recursos da língua e passam a exercer a função de enunciados, porque provocam no interlocutor um ato responsivo, ainda que passivamente. Desse modo, por meio desses recursos linguísticos os locutores orientam os interlocutores do jornal, de forma argumentativa, a refletirem sobre a atitude desses cidadãos, no sentido de não acreditarem em suas falácias quando se julgam 
"defensores da vida”, mas que são incapazes de defenderem a vida de uma criança de apenas dez anos, vítima de estupro durante quatro anos pelo próprio tio.

Além de apresentar elementos que orientam argumentativamente os interlocutores a pensarem e agirem conforme o contexto situacional, conferindo aos comentários uma dimensão argumentativa naturalmente construída por meio do discurso, podemos perceber claramente que os locutores idealizam e concretizam também uma empreitada persuasiva. A partir dos dados apresentados na notícia, os enunciadores organizam seus projetos de dizer com o uso dos traços linguísticos que, autorizados pelas características no âmbito discursivo que compõe os textos (interacionais, situacionais, temporais, proposicionais), integram o estilo, organizam a estrutura composicional, atendendo ao propósito comunicativo do gênero. O horizonte temático dos textos apresenta um acabamento enunciativo e uma relação estabelecida com o interlocutor bem marcados, evidenciando o aspecto valorativo do gênero comentário de leitor.

Ainda que esta análise dos aspectos verbais não tenha alcançado um nível aprofundado de investigação, tendo em vista não ser este nosso objetivo, depreendemos que as escolhas lexicais dos produtores, que exercem enorme importância na construção estilística dos textos, acionam informações necessárias à adesão dos interlocutores. Com base nas discussões analíticas, que contemplam as dimensões social e linguística dos comentários de leitor, defendemos que os enunciados que formam os textos analisados manifestam uma posição ideológica bastante clara, apresentando, portanto, não apenas uma dimensão, mas, também, uma visada argumentativa.

\section{CONSIDERAÇõES FINAIS}

Neste trabalho, objetivamos apresentar uma análise do gênero do discurso comentário de leitor, coletado em site jornalístico, observando como são construídos os aspectos argumentativos revelados por meio das características situacionais, interacionais, dialógicas e de alguns elementos linguísticos, que compõem o estilo, o tema e a estrutura composicional dos enunciados. Nas análises, realizadas com base nos estudos bakhtinianos e nas pesquisas de Amossy (2018), destacamos as relações dialógicas como componente motivador da argumentação presente nos comentários.

Seguindo o modelo de análise do enunciado proposto por Bakhtin e adotado por Rojo (2005) e Rodrigues (2005), analisamos os textos tomando como princípio o quadro genérico em que estes estão inseridos, cujos elementos sociais e comunicacionais foram evidenciados em primeiro plano. Em um segundo momento, analisamos alguns recursos linguísticos utilizados pelos comentaristas e considerados, neste trabalho, como elementos mobilizadores da argumentatividade. Em nenhuma das etapas tivemos a intenção de esgotar as possibilidades de investigação relacionadas a esses textos, pois elas são, a nosso ver, inesgotáveis. 
Nosso objetivo foi alcançado no sentido de, na prática, estabelecermos os caminhos que nos possibilitaram identificar características do gênero comentário de leitor, ampliando, assim, nossos conhecimentos enquanto estudiosas dos fenômenos linguísticos e, em especial, em torno da temática dos gêneros do discurso.

Em pesquisas dessa natureza, que visam uma investigação de cunho argumentativo - neste caso, sendo a argumentação no discurso a vertente privilegiada -, entendemos como necessária a articulação da teoria argumentativa com outros pressupostos do âmbito das pesquisas sobre o discurso. Assim, esse estudo adquire, a nosso ver, uma dimensão social muito mais ampla, aumentando também as condições de o pesquisador encontrar meios diferentes de compreender a língua em suas formas concretas de uso.

No gênero observado, a argumentatividade é construída na interação entre o enunciador e seus interlocutores, que não participam face a face da comunicação, mas exercem um papel relevante nas escolhas realizadas pelo locutor, cuja vontade enunciativa está atrelada à intenção de convencer e/ou persuadir seus parceiros quanto ao tema abordado. Nessa perspectiva, observar as peculiaridades do gênero em estudo, com sua natureza enunciativa mais ou menos estável, foi determinante na compreensão sobre a distribuição dos papéis sociais dos interlocutores e, consequentemente, sobre os demais elementos do gênero.

Nas análises, destacamos o olhar sobre a esfera jornalística como reguladora das relações e da força argumentativa dos enunciados que compõem o horizonte temático-discursivo do jornal. Os comentários de leitores, que possuem características de um gênero primário, oral, cotidiano, adquirem relevância social e proposicional quando inseridos em um suporte jornalístico como o Jornal Folha de São Paulo, assumindo aspectos de gênero secundário. Essa relevância observada no gênero analisado encontra respaldo em algumas questões sobre as quais refletimos durante a pesquisa: i) as relações dialógicas com os outros gêneros publicados no site, desde a notícia (texto base para a produção dos comentários) aos demais gêneros, como a charge e o cartaz, compondo, todos eles, a configuração temática dos textos; ii) os comentários publicados na seção "painel do leitor" apresentam a mesma orientação valorativa, comprovando o poder regulador da esfera jornalística no tocante aos fatores ideológicos sugeridos a partir da ancoragem desses comentários com os demais gêneros, principalmente com a notícia; iii) o estilo dos enunciados, resultante das escolhas lexicais e dos demais recursos linguísticos, é organizado de maneira a provocar a adesão dos interlocutores.

Acrescentamos, ainda, que na construção dessa arquitetura argumentativa, fundamental se faz considerar o contexto social de produção dos comentários de leitor. Ademais, reiteramos, como um componente essencial para a compreensão deste gênero do discurso, o permanente diálogo identificado nos comentários com enunciados de outros campos do saber, constituindo, desse modo, um aspecto determinante na caracterização e na construção argumentativa do gênero. 
Por fim, reforçamos que outras análises poderão ser empreendidas a partir das discussões propostas no presente estudo, especialmente por constituir uma abordagem analítica sustentada por preceitos teórico-metodológicos consistentes, cuja legitimidade acadêmica poderá fomentar reflexões que lhes preencham as lacunas e/ou que proponham novas investigações acerca da análise argumentativa direcionada aos gêneros do discurso.

\section{REFERÊNCIAS}

AMOSSY, R. A argumentação no Discurso. Tradução (coord.): Eduardo Lopes Pires e Moises Olímpio Ferreira. São Paulo: Contexto, 2018.

BAKHTIN, M. Os gêneros do discurso. Tradução: Paulo Bezerra. São Paulo: Editora 34, 2016. BRAIT, B. O texto nas reflexões de Bakhtin e do Círculo. In: BATISTA, R. O. (Org.). $O$ texto e seus conceitos. São Paulo: Parábola Editorial, 2016. 144 p.

RODRIGUES, R. H. Os gêneros do discurso na perspectiva dialógica da linguagem: a abordagem de Bakhtin. In: MEURER, J. L.; BONINI, A.; MOTTA-ROTH, D. (Org.). Gêneros: teorias, métodos, debates. São Paulo: Parábola Editorial, 2005. p. 152-183.

ROJO, R. Gêneros do discurso e gêneros textuais: questões teóricas e aplicadas. In: MEURER, J. L.; BONINI, A.; MOTTA-ROTH, D. (Org.). Gêneros: teorias, métodos, debates. São Paulo: Parábola Editorial, 2005. p. 184-207.

Recebido para publicação em: 17 abr. 2021. Aceito para publicação em: 13 jul. 2021. 